as shareholders to think long and deeply before they reject proposals which promise to deal so fairly with their interest in a society which is becoming increasingly organised upon a democratic ideal of public service through private enterprise. At the least, $\mathrm{Mr}$. Somervell's book should strip some of the woolliness from our thinking about industrial relations, and contribute towards a new constructive alignment of all groups participating in production or commercial enterprise, in which both economic and social purposes are fulfilled, and men and women can understand how their work is serving the community of which they are themselves a part.

\section{HELMHOLTZ'S THEORY OF HEARING UNDER VOLLEY FIRE}

Theory of Hearing

By Prof. Ernest Glen Wever. (Wiley Publications in Psychology.) Pp. xiii+484. (New York : John Wiley and Sons, Inc.; London: Chapman and Hall, Ltd., 1949.) 48s. net.

7 HE field of the special senses is a 'Tom Tiddler's ground' intruded on by prospectors from a dozen neighbouring territories of scientific study, each with its own techniques and its own language. A lingua franca has yet to be worked out. It is difficult at present for the zoologist to understand the findings of the clinician, for the psychologist to understand the physicist, and for the engineer to understand the anatomist; and a complacent misunderstanding is fatally easy, particularly about hearing. So it is not surprising that, although an appalling amount of nonsense has been written and published about auditory theory, books on it which are at once synthetic and authoritative and intelligible are few and far between. It is twelve years since "Hearing" by Hallowell Davis and S. S. Stevens set a very high standard. It can be surmised that this book gained enormously in clarity from the collaboration of a medically qualified physiologist with a psychologist. Its" weaknesses were on the physical and comparative sides; but within its limitations it was well arranged, exhaustive and very readable.

Now another psychologist has attempted a synthesis. Prof. E. G. Wever ought to be eminently qualified for the task: it was his discovery with C. W. Bray twenty years ago of the effect still known by their names which gave a new impetus to the physiological study of the ear. Moreover, he is one of the few men of science who have inquired into the auditory capabilities of animals, and who might in consequence have escaped the narrowly anthropocentric attitude which misled even Helmholtz and has been a curse to the subject ever since. Here surely should be the balanced and up-to-date survey we have been waiting for.

This anticipation is not altogether fulfilled. Of the three parts into which the book is divided, the first is a useful and comprehensive, but rather uncritical, survey of the history of auditory theory. The second part attempts to evaluate the principal theories by setting them in relation to the facts of observation. The argument is here weakened and diluted by the author's failure to distinguish problems peculiar to auditory theory from general problems of perception. When he says, for example, that Gray's principle of maximal stimulation "saved the day" temporarily for the resonance theory, he is introducing a red herring. It may safely be assumed that a pure tone is heard as a pure tone for the same reasons that a pencil point on the skin is felt as a single point, although in both cases many receptors are excited in differing degree. What these reasons are is, no doubt, a problem; but it is not specifically an auditory problem, and it does not affect the validity of the resonance theory either way. The objections here raised to the resonance theory all vanish like mist before the sun of a critical examination, and not all of them are correctly stated or based on established fact. It is difficult not to believe that the author has deceived himself as to their weight in his devotion to his own volley theory, the development of which occupies the third and by far the largest part of the book.

The essence of the volley theory is that a judgment of pitch depends not only on the particular fibres in the auditory nerve which are excited by a tone, but on a particular temporal relation between the impulses in these fibres and the sound waves imping. ing on the tympanic membrane. For middle and lower frequencies, the second factor is considered to be predominant. In my opinion, this theory is redundant, but there is nevertheless in this part of the book a valuable compendium of experimental data. In faimess to the author, it must be said that he often allows the facts to speak for themselves and has frequently resisted the ever-present temptation of the theorist to select the evidence which makes his case. But it is not always so. For it is well established that pitch discrimination is at its best at 1-12 kc./s., and in this range is roughly constant at about $1 / 30$ semitone. Below $1 \mathrm{kc} . / \mathrm{s}$. the least discriminable interval rises steeply to more than a whole tone at the lowest audible frequencies. But the author on p. 333 says : "It is of interest that in the middle range, where according to the [volley] theory there is both spatial and frequency repre. sentation, the discrimination is no better than in the low range [my italics] where frequency serves alone. It appears that the frequency cue is so much the more accurate that the presence of the other is of no appreciable benefit to this function." Here, where the facts are destructive of his theory, he has inverted them in its support.

Lapses into obscurity, sporadic throughout the book, become continuous when the author is discussing the physical aspects of hearing. For examply, the sentence (p. 37) "No resonance is wholly specific" appears to mean "No resonator has only a single resonant frequency", whereas from the context it can be inferred that the intended meaning is "No (real) resonator is indefinitely selective"-a truism which might well have been omitted. In many other places the obscurity is not dispelled, even by a careful study of the context; and occasionally a blatant error shakes the reader's faith. Fig. 115, ostensibly an oscillogram of the combination of frequencies of 1,000 and $1,001 \mathrm{c} / \mathrm{s}$., is clearly not what it pretends.

But in spite of obvious failings the book is a considerable achievement. It is, in fact, one of the three or four books on hearing published since Helmholtz's time which allow of serious criticism; and, while it is probable that most students of the subject will be amused or exasperated by it according to their temperament, it is also probable that few will be able to afford not to buy it.

$$
\text { R. J. PUMphrey }
$$

